\title{
The MAPS model of self-regulation: Integrating metacognition, agency, and possible selves
}

\author{
Leslie D. Frazier $^{1}$ (D) Bennett L. Schwartz ${ }^{1} \cdot$ Janet Metcalfe $^{2}$
}

Received: 3 April 2020 / Accepted: 24 November 2020 / Published online: 6 January 2021

(C) The Author(s), under exclusive licence to Springer Science+Business Media, LLC part of Springer Nature 2021

\begin{abstract}
Self-regulation, a social-cognitive process at the intersection of metacognition, motivation, and behavior, encompasses how people conceptualize, strive for, and accomplish their goals. Selfregulation is critical for behavioral change regardless of the context. Research indicates that self-regulation is learned. Integral to successful self-regulation of behavior are: (a) an articulated concept of one's possible selves, (b) metacognitive knowledge and effective strategies, and (c) a sense of one's own agency. We present the theoretical linkages, research evidence, and applied utility for these three components in promoting self-regulation of behavior, specifically in the domain of learning. We propose the MAPS model to account for the pathways of influence that lead to behavioral change. This model illustrates the dynamic and feed-forward processes that derive from the interactions among possible selves, metacognition, and agency to provide the context for developing self-regulated and effective learning that promotes student success, the transfer of knowledge, and the foundation for life-long learning.
\end{abstract}

Keywords Self-regulation · Possible selves $\cdot$ Future selves $\cdot$ Metacognition $\cdot$ Agency $\cdot$ Learning

An elderly woman with lung cancer is anxious about the spread of coronavirus (COVID-19) in her city and is wondering what she can do to protect herself against the threat from this virus; her goal is to stay healthy. A first-semester college senior has an amazing internship lined up, but because of poor time management she is now at risk of failing out of two of her classes, which will prevent her graduation and put the internship out of reach; her goal is to get back on track academically. A middle-aged man is told by his supervisor that unless he changes his sales strategies and meets the company's required sales quota for the next quarter, he is at risk of losing his job; his goal is to increase sales and hold on to his job. A male graduate student from a minority background experiences racial abuse (Kendi 2019; Pierce 1970; Sue et al. 2007) on a daily basis, his stress level is increasing, he is having difficulty coping, his productivity and health are

Leslie D. Frazier

frazier@fiu.edu

1 Department of Psychology, Florida International University, Miami, FL 33199, USA

2 Department of Psychology, Columbia University, New York, NY, USA 
suffering, and he is considering dropping out of graduate school; his goal is to better cope with race-related stress. What do each of these hypothetical scenarios have in common? Each, in different ways, poses an issue of how to motivate and enact self-regulation so that it is possible to reach one's goals, whether those goals are avoiding threats to one's health, improving one's grades in school, increasing sales, or controlling adverse responses to racial abuse.

Self-regulation - the processes through which individuals control and direct their thoughts, emotions, and behaviors to achieve goals - has been linked to many adaptive skills and desirable mental and physical outcomes across the life span (Wrosch 2011). Whether the person is motivated by a desire to be healthy and fit or to land that ideal internship, to sustain and nurture an important relationship, to achieve financial success, or even to acquire expertise in a knowledge domain, self-regulatory skills are necessary. Promising theories, empirical research, and applications to enhance self-regulation to change behavior in the domains of learning has focused, separately, on (a) our concept of ourselves and of the future self we wish to become, (b) our metacognitive knowledge and the strategies we recruit to achieve our goals, and (c) our sense of our own self-efficacy or agency. All three of these domains are instrumental in achieving goals. However, although each of these domains have been extensively researched, individually, there is currently no theoretical model that smoothly integrates all three of these components of self-regulation into a single interactive model (but see Efklides and Tsiora 2002 for a discussion of self-concept and metacognition). Here we propose a dynamic and fully interactive model of self-regulation that brings together these three constructs (see Fig. 1).

In this article, then, we articulate the unique individual, coactive, and synergistic influences of these three components of self-regulation. In doing so we bridge the gaps in the selfregulation literature to build a model with implications for many domains of psychology. Although we focus on learning, our model is intended to generate theoretical, empirical, and translational research across other and varied domains.

The model that we propose represents the dynamic, reciprocal, and evolving interactions among the components of self-regulation that represent: (a) the embodiment of goals- notions of what we can become- that motivate behavior (i.e., future selves or possible selves), (b) the means of change in the form of the process and application of strategies and techniques to implement goal-directed actions (i.e., effective metacognitive and control strategies), (c) the effect of our actions in terms of our sense of self-competence, self-efficacy, and active engagement (i.e., agency), and finally, (d) the behavioral outcome (i.e., goal achievement or discrete sub-goals toward goal achievement), that results from specific decisions, actions, and behaviors that the individual takes from working toward their desired goals. As is shown in Fig. 1, we propose that each construct independently influences behavior, but they also feed back on the other components in a dynamic manner. For example, a student studying for a physics exam might have a vision of the future - a 'possible self' of becoming an outstanding student. But to do so he or she needs to employ useful metacognitive strategies to guide studying and improve the chance of getting a good grade. Studying will be more effortful and the outcome more meaningful if it is driven by the student's hoped-for self of being a person who excels at physics. Putting these metacognitive strategies to good use to favorably affect this outcome, and observing the improvement, results in the person feeling more effective, and that affects one's sense of agency. They feel that their efforts have paid off, and that they are in control. Self-efficacy increases. Now, feeling themselves to be a more effective person, their motivation - driven by the desire to become an even more masterful and effective person increases. 
MAPS Model

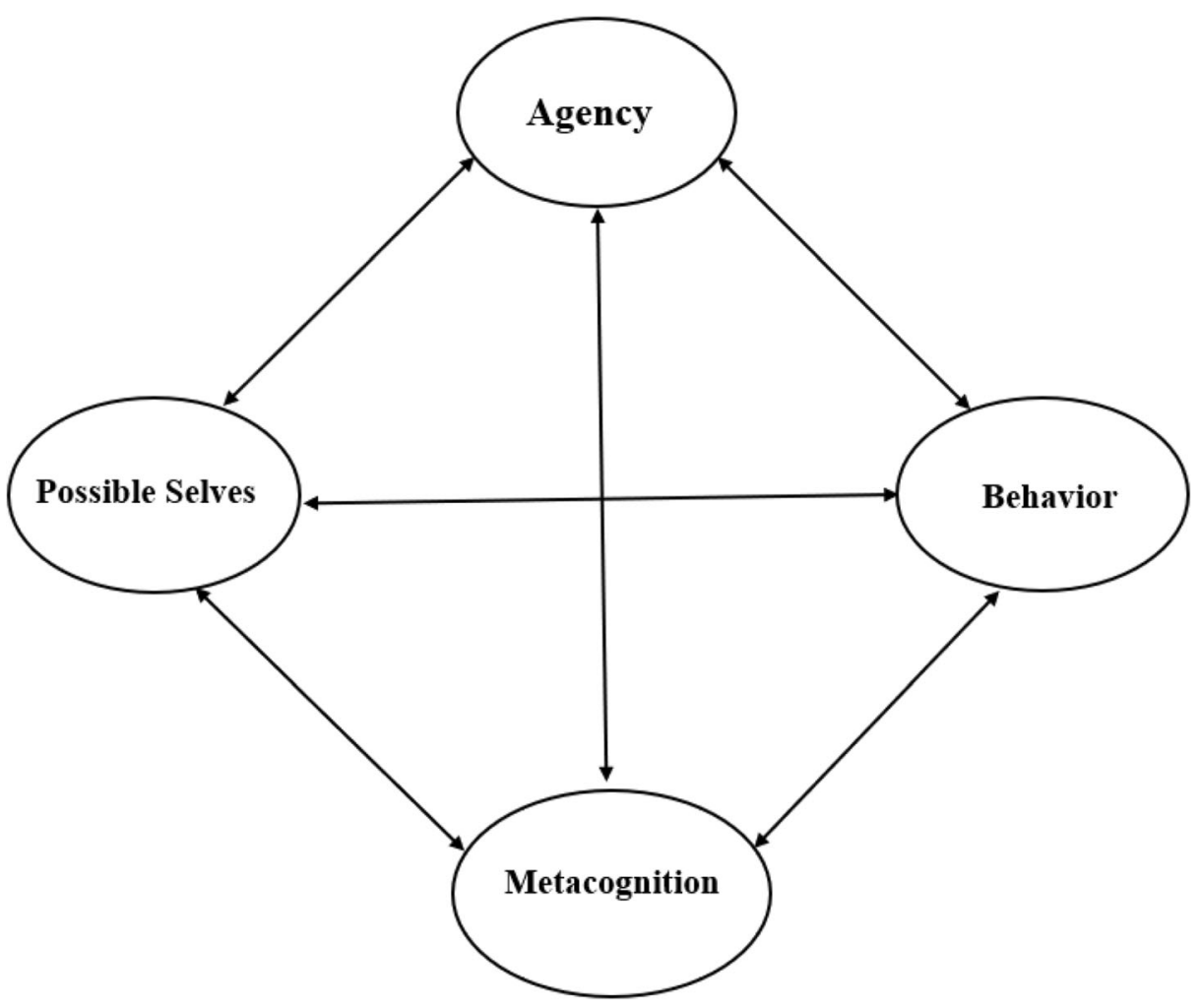

Fig. 1 The MAPS Model: The MAPS model of self- regulation displays how the process of self-regulation is influenced by one's possible selves, metacognition, and a sense of agency

The motivational weight of possible selves derives from one's sense of agency, and agency drives one to work toward goals, especially in the face of obstacles. A goal does not become embodied in a sense of self without a sense of being able to enact actions to achieve it. Thus, in pursuit of a goal - in the form of a future self that one is trying to become (or, indeed, to avoid becoming) - individuals are continually monitoring their cognitions, actions, and outcomes and revising their efforts in light of their goals. Efklides and Tsiora (2002), for example, showed that a stronger self-concept positively predicted a number of metacognitive states such as feelings of confidence and effort put forth. The MAPS model provides an understanding of the influences on goal disengagement as well. Although control-process models of selfregulation (vanDellen and Hoyle 2008) and expectancy-value motivational approaches suggest that people who expect to reach a goal will effortfully engage when they experience constraints or obstacles (Fisher and Oyserman 2017; Oyserman 2019; Scheier et al. 2014; Seligman 1991; Smith and Oyserman 2015; Wrosch et al. 2003), sometimes disengaging from a goal, especially when persistence could lead to undesirable consequences, is a necessary part of self-regulation (Wrosch et al. 2003).

Self-regulation (or the lack thereof) can be interpreted in light of the self-concept (Ko et al. 2014; Horowitz et al. 2020; Oyserman 2019; Oyserman and Dawson 2019; Oyserman et al. 
2004, 2017; vanDellen and Hoyle 2008; Vohs and Baumeister 2016). Possible selves, metacognition, and agency shape decisions to modify or abandon goals independently and through their interactive influences. Effective metacognitive control strategies represent the ongoing dynamic self-reflective processes that guide individual choices and behaviors and ultimately get one to the goal. Both metacognitive processes and agency provide ongoing feedback to guide the dynamic process of behavioral change.

In the sections that follow, we present the extant theoretical and empirical foundations of each of the three components that comprise the MAPS model and highlight how, when they are combined into one comprehensive integrative model, our understanding and efficacy at predicting self-regulatory behavior in learning is improved. Thus, the MAPS model can be a powerful tool to enhance learning across different contexts throughout life.

\section{Possible selves: Motivation and goal striving}

People make sense of their experiences through the lens of the self. Self-knowledge, and the sense of one's self as being an effective, self-reliant agentic person, is predictive of behavior. For example, information interpreted in light of self will be more deeply encoded, be stronger motivationally, and be more likely to be maintained and recalled over time (Hooker 1999; Sui and Humphreys 2015). Our self-conceptions represent our theories of ourselves, past, present, and future (Lee and Oyserman 2009; Oyserman and Dawson 2019) and are presumed to be relatively stable and consciously available (Frazier and Hooker 2006; Oyserman 2019). Our drive to make meaning from our experiences shapes and is shaped by our self-concept.

A component of the self-system that drives motivation and is strongly predictive of behavioral engagement in service of goal attainment is the concept of possible selves (Brandtstädter 1998; de Place and Brunot 2020; Frazier and Hooker 2006; Hooker 1992; Leondari et al. 1998; Markus and Nurius 1986; Oyserman 2019; Oyserman and Dawson 2019; Oyserman et al. 2015; Oyserman and Markus 1990; Ryff 1991; Smith and Freund 2002). Possible selves (also called future selves) are our future visions of ourselves, our identities projected into the future, and the embodiment of the goals we aspire to or the outcomes that we fear (Frazier and Hooker 2006; Higgins et al. 1994; Hooker 1992; Markus and Nurius 1986; Stokes 2019). Our possible selves are images that we mentally concoct of the person that we hypothetically imagine ourselves becoming as a result of following one path of behavior or another. Temporal, contextual, developmental, and cultural factors influence possible selves, and possible selves often represent teleonomically relevant change - change that is unique to the individual (Allport 1937; Frazier and Hooker 2006; Hooker 1999).

Possible selves possess motivational and self-regulatory functions that operate within three distinct components: valence (positive selves vs negative selves), elaboration (general vs specific), and discrepancy between current and future selves (Oyserman and Fryberg 2006). Oyserman and colleagues have argued that possible selves are more likely to be effective in their self-regulatory function when they provide specific and detailed future images linked with strategies that connect current behaviors to future states. They also assert that people with highly developed possible selves are more likely to set self-defined, specific goals, plan strategies to achieve them, and tend to persist when confronted with difficulties than people with general, less well-developed possible selves (Oyserman et al. 2004). These tenets have implications for the implementation of intentions that individuals have for their goals. 
Future possible selves have valence - hoped-for selves (those we want to achieve) and feared selves (those we want to avoid) - both of which influence our thoughts, choices, and behaviors on a day-to-day basis. Better outcomes occur when possible selves are balanced (Frazier et al. 2000; Oyserman and Markus 1990) or matched (Smith and Freund 2002) - the presence of countervailing hoped-for and feared selves in the same domain (e.g., "to be a cancer survivor" and "for my cancer to return"). This balance incorporates both approach and avoidance or promotion and prevention foci of self-regulation (Higgins 1998; Higgins and Cornwell 2016; Ko et al. 2014, but see Quinlan et al. 2006).

The concept of balance among hoped-for and feared possible selves has led to the development of two relevant theories. First, regulatory focus theory (Higgins 1997, 2000), an outgrowth of self-discrepancy theory, emphasizes that self-regulation operates differentially in the service of different demands or needs. Second, self-discrepancy between the actual/ current self and the future hoped-for (which could also be an "ideal," or "ought" self) is an important motivator for self-regulation and behavior change. Self-discrepancy theory (Higgins 1987, 1989) argues that these discrepancies fuel self-regulation of cognition, motivation, emotions, and behavior (see also vanDellen and Hoyle 2008). Discrepancies among the possible self and the immediately present self prompt engagement in metacognitive strategies that increase likelihood of goal achievement, or, conversely, may occasionally lead to disengagement from the goal and a reimaging of the possible self. The self-discrepancy makes you want to change, but metacognition and agency are necessary for engaging in the actions that lead to change.

Possible selves, then, are a self-regulatory and motivational resource (Aloise-Young et al. 2001; Oyserman 2019; Oyserman et al. 2006; Nurius et al. 2006; vanDellen and Hoyle 2008; Vignoles et al. 2008). However, possible selves alone cannot instantiate goal attainment. They represent the desire for change but not the means to enact it. As Oyserman and colleagues point out one needs the 'destination as well as the path' (Oyserman and Lewis 2017, our emphasis). We will shortly articulate the coactive roles of the additional components of the MAPS model that work in conjunction with possible selves to regulate behavior, and to provide that path. In the next section, though, we review evidence demonstrating how possible selves motivate behavior in the domain of learning.

\section{Possible selves and learning}

Research has shown, within the context of learning and academic achievement, that thinking about possible future selves is associated with student success (Altintas et al. 2020; Cadely et al. 2011; Dietmeyer et al. 2013; Erikson 2019; Oyserman et al. 2006; Smith and Oyserman 2015). Learners who indicate that they have "success selves" show greater persistence and effort in problem solving and greater mastery of learning (Ruvolo and Markus 1992). Success selves are especially potent motivators of behavior when there is a good fit among successselves and the contexts that support success (Oyserman 2019; Oyserman et al. 2015; Smith et al. 2014). In terms of the MAPSs model, such success selves may be bolstered by positive feedback from the agency component of the model - as a result of people's perception that their own effort is effective.

Altintas et al. (2020) used a method called the Best Possible Selves Intervention (Peters et al. 2013), a protocol (see also King 2002) designed to elicit possible selves by having participants mentally think about a specific situation (either an 'ideal academic' future self in the experimental condition or in the control condition neutral information about the university 
campus) that is presented on a computer screen. Participants were then asked to fill out a questionnaire. Altintas et al. found significantly higher scores on measures of positive affect, academic commitment, and academic motivation in the experimental group when compared to controls. However, these effects were mediated by positive affect. Unlike other, more applied interventions, this study did not measure change in possible selves or academic performance over time.

Across many studies, Oyserman and her colleagues (see Horowitz et al. 2020; Oyserman and James 2011) have shown that students with academic possible selves (those that emerge organically and those that emerge in response to intervention) demonstrate increased academic initiative, higher standardized test scores, better grades and lower rates of school absences, fewer in-school behavioral problems, and lower rates of depression, than do students who did not have academic possible selves. The more descriptive or articulated one's possible selves are, the more effective they are in regulating behavioral outcomes (Oyserman et al. 2004; vanDellen and Hoyle 2008). Oyserman's research has led to the development of the identitybased motivation theory (Oyserman 2019; Oyserman et al. 2015; Oyserman and Dawson 2019). This theory emphasizes the important motivational influence of accessible possible selves, as well as the importance of the contextual sensitivity and fit among the context and one's future identities. Oyserman and colleagues have shown that possible selves are associated with motivation (Oyserman et al. 2015; Oyserman and Fryberg 2006, Oyserman and James 2008), academic outcomes (Oyserman et al. 2004), and a positive school experience (Oyserman et al. 2006). Although the early studies were correlational, they gave rise to the question of whether it might be possible to develop an intervention based on creating positive possible selves. Several studies have explored this possibility.

In a recent review of possible selves intervention studies, Horowitz et al. (2020) found one randomized intervention trial that showed that changing academic possible selves affects subsequent academic outcomes (Oyserman et al. 2002). This study was noteworthy due to the measurement of change in possible selves and the measurement of change in academic outcomes. Horowitz et al. found an additional six studies that focused on changing possible identities (though possible identities were measured in different ways; Carroll et al. 2009; Kerpelman and Pittman 2001; Kortsch et al. 2008; Lee et al. 2015; Oyserman et al. 2002; Stake and Nickens 2005). Oddly, none of these studies demonstrated that changing possible identities led to changes in academic trajectories. According to Horowitz and colleagues (Horowitz et al. 2020), the lack of success in all but one of these intervention studies is important because "the idea that change in possible identities occurs and matters is, implicitly or explicitly, the basis for a large number of interventions" (p. 28) implemented in various academic settings and educational levels (e.g., middle school, high school, college). It may be that the failure of these interventions has to do with the complex interactions among possible selves, metacognition, and agency - and the MAPS model may provide the conceptual framework for effective interventions that lead to change in both sense of self and academic achievement. Thinking about possible selves can be beneficial and lead to desired outcomes. But goal achievement is increased when goal-striving and possible selves work in tandem with metacognitive strategies to enable long-term behavioral change.

We propose that the role of possible selves is to motivate self-regulation. However, having motivation or desire is not enough - there also must be a way to implement the desired change. Although the strategies needed to implement changes have sometimes been used to good effect within the possible selves tradition (see Oyserman et al. 2004), the need for metacognitive strategies is often not well articulated. Gollwitzer and Sheeran (2006) have shown that in order 
to effect change, people also need, not only to have a goal, but also to activate what they call "implementation intentions." Implementation intentions - typically a volitional strategy specify the "when, where and how" and have the structure "if this situation happens, I will do Y." They are subordinate to goal intentions (Gollwitzer 1999). As such, implementation intention is the first step towards metacognition. They link motivation and goals, to a means to begin to achieve those goals. Thus, in the MAPS model, people's implementation intentions lead to the active strategy knowledge and use embodied in the metacognition component of the model.

Moreover, in addition to being motivated to become the person one imagines one's desirable possible self to be, and of having the metaknowledge and strategies to implement that desire, people need to be able to monitor their own success or failure and have a feeling of agency - to feel that they are, indeed, capable of doing the things that need to be done in order to achieve that desired self. Agency has been discussed in relation to possible selves since the possible selves concept was first introduced by Markus and Nurius (1986). But the mechanisms through which agency itself is perceived, and how that knowledge of one's own causal role in bringing about change feeds back into one's self-concept (and possible selves) - by increasing one's motivation - has received little examination. The sense that one has the capability to reach a desired outcome is, we argue, the third component of the regulatory mechanism for behavioral change and is needed for the achievement of favorable outcomes (Erikson 2007; Knox 2006).

\section{Metacognition}

In the MAPS model, we take a broad view of what constitutes metacognition. We include in our conception of metacognition our thoughts and beliefs about cognition, our feelings and experiences about cognition, and the strategies we use to affect change in our cognition and behavior (Dunlosky and Tauber 2014; Kuhn 2000; Winne 2018). This conception follows from Flavell's (1979) introduction of metacognition as our knowledge and experience of our own cognitive processes. Metacognitive knowledge refers to explicit information that we possess (correctly or incorrectly) about how our cognition works, whereas metacognitive experience refers to the feeling we have about what we know and what we will learn (Metcalfe and Schwartz 2016; Nelson and Narens 1990). We broaden this view to include strategies and beliefs. In our view, metacognition, allows for self-regulation through the processes of metacognitive control (see Efklides 2011; Hertzog 2016; Nelson and Narens 1990).

Concepts of metacognitively-guided self-regulation have been extensively studied in educational psychology (e.g., Azevedo 2015; Boekaerts 1996; Efklides 2011; Zimmerman 2013) as well as in cognitive psychology (e.g., metacognitive control, see Bjork et al. 2013; Nelson and Narens 1990). Conceptually, the terms metacognitive control and self-regulation have often been linked and are sometimes used interchangeably, although they have unique roots within the psychological literature (Dinsmore et al. 2008). In the current usage, self-regulation subsumes the processes typically thought of as metacognitive control (Toppino et al. 2018). Here we distinguish self-regulation in terms of the strategies, actions, or behaviors we engage in, and metacognitive control as specific internal processes that direct behaviors that can help cognition. Domain-specific self-regulated learning is the process that involves cognitive, metacognitive, motivational, behavioral, and affective facets of learning. To summarize, metacognition through control processes directs behaviors that we engage in to achieve a 
particular goal, whether that is learning or some other objective, whereas the behaviors engaged is what we are calling self-regulation.

Metacognitive strategies are the tactics that we employ to achieve metacognitive control (Wells 2008). Thus, a person may employ distributed study because that person has metacognitive knowledge that distributed study improves learning efficiency. In essence, metacognitive strategies provide blueprints for metacognitive control, which, in turn achieve self-regulation (Lajoie 2008 but see Koriat et al. 2006 for a different view). Most of us are motivated by a strong desire to actively shape our experiences and our lives, this is the nature of goal striving (Heckhausen et al. 2019) particularly, as noted in the preceding section, when energized to do so by consideration of our future or possible selves. Strategies used on a daily basis and over the course of goal striving have not been well understood, which is partially why we have advanced our model, applicable across domains (but see Haase et al. 2013; Rothbaum et al. 1982; Schunk 2008). Metacognition involves an ongoing dynamic between monitoring, the ability to judge one's own cognitive processes, and control, the ability to use those judgments to alter behavior (Dunlosky and Ariel 2011; Son and Schwartz 2002). Thus, if a student stops studying for a calculus exam based on a metacognitive judgment (say, the assessment that he or she has sufficiently mastered the material to reach the goal of either getting an " $\mathrm{A}$ " or a "C", say, depending on his or her possible self-related goals), the decision to terminate study is a part of metacognitive control (and the act of termination is selfregulation). For example, Mason et al. (2010) found that when students had more explicit metacognitive knowledge about their own knowledge of science then they were better able to learn new information in an online format. Muis et al. (2015) also found that participants who could better assess their own knowledge learned information about global climate change more quickly. Sahakyan et al. (2004) looked at a judgment they called aggregate judgements of learning (JOLs), which was an estimate of how many items participants would free recall from a list. They compared students who made aggregate JOLs to those who did not. In keeping with the view that metacognition informs control and self-regulation, the students who made the aggregate JOLs used more effective encoding strategies on subsequent lists than those who did not make aggregate JOLs. In other words, being asked to be metacognitive by the prompt to make aggregate JOLs caused the students to be more reflective and use more effective strategies. Similarly, Soderstrom et al. (2015) found that the act of making a judgment of learning led to better recall, at least for related pairs. Thus, there are positive correlations between the ability to monitor and effective control.

To summarize, metacognition informs self-regulation, which is necessary to shape decision-making and action. Specifically, the enactment of any strategy that involves appraisal, monitoring or control of thinking is a self-regulatory process. However, metacognition does not require self-regulation just as self-regulation does not require metacognition. As such they complement each other to motivate goal striving and behavioral change.

\section{Models of metacognition and self-regulation in learning}

A seminal model of self-regulated learning was devised and tested by Zimmerman (1986, 2000, 2013). As this model developed and evolved over time, it has been applied to address the question of how individual learners develop more intricate and accurate cognitive models and how they become experts at specific tasks (Panadero 2017; Winne 2018). It also has had durable influence over many researchers in the field of self-regulation (see Schunk and Greene 2018; Sinatra and Mason 2013). Zimmerman's (2000) Cyclical Phases Model breaks the 
process of self-regulated learning into three phases: forethought, performance, and selfreflection. In the forethought phase, goal setting, task analysis, strategic planning, and motivational beliefs drive the processes and influence the choices and activations of specific learning strategies. In the performance phase, the previously planned actions are executed in tandem with self-monitoring. Self-adjustment and control strategies are employed to maintain engagement, motivation, and successful completion of the task. Finally, in the self-reflection phase, performance on the task is assessed. Self-assessment of successes and failures are noted. These serve to guide future learning and task performance. Thus, Zimmerman's model integrates aspects of learning, aspects of metacognition, and aspects of people's selfregulatory mechanisms.

Zimmerman's model has been supported by empirical research in both academic domains and in the training of athletic skills (Panadero 2017). For example, Cleary et al. (2012) found that many people learning to shoot basketball free-throws adopted such a three-part procedure (e.g., forethought, performance, self-reflection). The more similar the strategies that participants used were to Zimmerman's three-part sequence, the more they improved in their shooting. Kitsantas and Zimmerman (2002) also used a sports paradigm. They found that for both experts and non-experts, volleyball serves improved when participants used specific self-regulated learning skills akin to Zimmerman's model. DiBenedetto and Zimmerman (2010) found that high school students studying science showed increases in knowledge and achievement when they had more knowledge of self-regulatory strategies. Similarly, Cleary and Sandars (2011) found that medical students who employed better self-regulatory strategies improved both their surgical technique and their knowledge of the surgical procedure more than did students with less knowledge of strategies. Zimmerman and Bandura (1994) assessed metacognitive knowledge about participants' own writing skills or what they called selfefficacy. Those with greater self-knowledge wrote more complex and better-organized essays. Finally, Steiner et al. (2020) found that students who were more accurate in their judgments of learning acquired more text-based information later. These are just a sampling of the research that support the general outline of Zimmerman's model (Zimmerman 2000, 2013).

Zimmerman's model has led to the development of several assessment tools to determine the phases, subprocesses, and efficacy of self-regulation in different learning contexts, empirical settings, and as potential interventions (Zimmerman 2013). These tools are questionnaires, which may be useful in both research and clinical settings. Thus, Zimmerman's work has both set up a useful framework for examining self-regulation in learning and developed applications that researchers can use to measure self-regulation in any domain. Furthermore, other similar models have sprung from Zimmerman's original conception. These include the COPES (Conditions, Operations, Products, Evaluations, Standards) model (Hadwin et al. 2018; Winne 2014, 2018), and Pintrich's (2000) Self-Regulated Learning (SRL) model. Our goal here is not to evaluate the relative merits of each model (but see Panadero 2017), but rather to describe the highly theory-driven nature of self-regulation research.

Returning to the issue of intention and overarching possible selves, we ask: What causes a person to follow through on intentions and enact effective self-regulation? One such reason may be the role of emotion in metacognition and self-regulation. Efklides and her colleagues developed a model that focuses on the roles of emotion and metacognition in self-regulated learning (Efklides 2008, 2011; Efklides et al. 2018). This model, the Metacognitive and Affective Model of Self-Regulated Learning, emphasizes how metacognition and affect influence goal setting, learning, and the regulation of the cognitive and affective processes needed for task performance and achievement. In particular, emotion has the ability to increase 
adaptive self-regulatory behaviors, if the person is in an emotionally positive state. However, emotion also has the ability to decrease adaptive self-regulatory behaviors, if the person is an emotionally negative state.

Demonstrating what individuals do in real-world learning situations and providing points of intervention to optimize learning is a strength of the Efklides model. For example, the model predicts that when emotions are positive and metacognition is accurate, more learning should occur. Efklides and her colleagues (Efklides et al. 2006; Efklides and Petkaki 2005) used selfreports of both affect and metacognitive knowledge. They found effects of induced negative mood (sadness) on feeling of difficulty and self-reported effort. However, the best predictor of effort was feeling of difficulty and positive affect, which suggests that positive affect provides the resources for effort exertion. From our perspective, this would suggest that affect impacts metacognitive knowledge, metacognitive experiences, and more importantly, metacognitive control. We emphasize the important contribution of Efklides' emotion-based model to articulate the implications of affect in the self-regulated learning process. This leads us to the next component of our model, and that is the role of agency, that is, our own sense of control over our life, has on ongoing self-regulation.

\section{Agency: Competence and engagement}

Agency has overarching effects on the processes and outcomes of the other components in MAPS. Consistent with Bandura (1989, 2001, and see Metcalfe and Greene 2007), we define agency as the exercise of control over our own thought processes, motivation, knowledge, and actions. The sense of agency - the perception of ourselves as self-determining people, having responsibility for our own actions and exercising control over our own outcomes - is foundational to our understanding of ourselves as human beings. It is through agency that we are able to make changes in ourselves and our situations. Agency both directly and coactively impacts self-regulation in the service of behavior change. Effortful and successful pursuit of goals, over time, provides us with a greater sense personal agency over our lives (Heckhausen et al. 2019). Agency bolsters our motivation to take action as needed and helps us to overcome obstacles in the implementation of our intentions (Efklides, personal communication), because our own strong sense of agency provides us with assurance that our actions can be and usually are effective.

The sense of agency is linked to possible selves, and incorporated- as a special characteristic- in people's self-concepts. A strong sense of agency provides the assurance that the individual can effectively become who he or she wants to become. In contrast, if the sense of agency is thwarted, and people feel little assurance that their efforts will pay off, they feel helpless and disempowered. Without a strong sense of agency even well-articulated and vividly imagined future selves may be perceived as being impossible to attain, and even excellent metacognitive strategies may come to naught. For this reason, we include agency as a foundational component of the MAPS model. For behavioral change to occur, it is essential that the person is actively engaged. The agentic individual is the source of the decisions and processes that drive the other MAPS components. The agentic individual: (a) is motivated by the discrepancy among current and possible selves, (b) implements effective metacognition and control processes, (c) actively engages in the behaviors that lead to specific desired outcomes, and then (d) accepts responsibility - blame or credit - for those outcomes. In this section, we review several studies that experimentally investigate cognitive processes, such as 
learning and value attribution, as a function of active (as opposed to passive) involvement in decisions and responses. Thus, we posit that being active rather than passive, and taking responsibility for being in control, is seminal for self-regulation (i.e., Bandura 1989).

The second aspect of agency that impacts the other components of the MAPS model is people's perception of their own agency, and the integration of feelings of self-efficacy into their future self. People may often evaluate their own agency in particular situations. For example, a person may judge that they can learn quantum physics, but that they cannot control the quality of instruction from their professor. These judgments of agency are derived from assessing the extent to which they actually have control over what they are attempting to do. They need to feel themselves to be in control of (a) the metacognitive plans, strategies, monitoring, (b) the control processes, and (c) the behavioral outcomes (Bandura 1999; Dweck 2006, 2018; Metcalfe and Greene 2007). This feeling of being agentic — of being in charge of one's life, and the outcomes of one's mental and physical actions - is incorporated as a central and defining feature of the self-concept and possible selves. Positive self-appraisals of this sort are critical for possible selves and allow the individual to envisage him or herself as an actor capable of forward change.

\section{Effects of being active rather than passive}

Merely being the agent has consequences for self-regulation, and by extension, learning, even when 'being the agent' simply means making an active choice rather than passively following a request. For example, Cloutier and Macrae (2008) showed that when people, themselves, picked random trait adjectives (without even knowing what they were) to remember rather than having the adjectives selected by another person, their memory for the words was better. It might be argued that perhaps people superstitiously thought that the self-selected words had some special meaning, and therefore they encoded them more deeply. And, indeed, when we relate to-be-remembered material to ourselves, we do, in fact remember it better (Leshikar et al. 2015). However, Murty et al. (2015) showed that the mere act of selecting resulted in enhanced memory even when the materials were random, neutral, non-self-relevant, and unknown at time of choice and the motor actions were held constant. In addition to these 'limiting case' experiments, there are many experiments that have shown that self-generation of answers (e.g., generating the answer 'banana' to "What is the fruit that begins with $\mathrm{B}$ ," as opposed to just reading "A fruit that begins with B is Banana") has a beneficial learning/memory effect regardless of what the materials are, how they are tested, and of virtually all characteristics of the participants involved in the experiments (see Bertsch et al. 2007; also see Slamecka and Graf 1978). Exerting agency in choosing what to study, and actively engaging in generation rather than passively being presented with materials has a pervasive effect on learning. The active engagement entailed when one feels oneself to be the agent, then, results in enhanced learning and retention.

Moreover, the benefit of self-generation accrues even when what the person generates is an error (although, of course, errors do need to be corrected). It is better to generate an error and receive the correction than it is to simply receive the correct response from the outset (Kornell et al. 2009; Metcalfe 2017). This benefit suggests that people should embrace errors rather than being needlessly fearful of making mistakes. Doing so not only fosters a more agentic stance, but it improves learning. Furthermore, it is far better to make one's own mistakes than listen to the mistakes of others (Metcalfe and Xu 2017). The benefits of active agentic participation, as compared to passive learning, play out fully in the classroom as well as in the lab (Freeman 
et al. 2014). Classroom learning is better when the instruction is in an active mode rather than passive mode to the point that professors are, correctly, admonished to "teach more by lecturing less" (Knight and Wood 2005). This empirical evidence demonstrates the role of agency in metacognitive and self-related contexts and shows how critical agency is for selfregulation generally and within the context of goal striving.

\section{Effects of the perception of agency}

According to Metcalfe and Greene (2007), "the feeling that we are agents, intentionally making things happen by our own actions, is foundational to our understanding of ourselves as humans (p. 184)." The feeling of agency reflects a belief in our own free will that is necessary for motivated action. Goal striving is based on the belief that we have the capacity to take purposeful initiative that will produce a favorable outcome, or to put another way, to engage in behavioral change of one's own free will. Across many experiments, the individual's perception of the goodness of an outcome is associated with their judgments of agency (Metcalfe 2013; Metcalfe et al. 2010; Metcalfe and Greene 2007; Metcalfe et al. 2012; Miele et al. 2011). Good outcomes are associated with high judgments of agency, whereas poor outcomes tend to be associated with low judgments of agency. This correlation holds across many populations, including elementary school children, college students, older adults, and even people with Asperger's syndrome, and schizophrenia (Metcalfe 2013). Bucknoff and Metcalfe (2016) showed that people, too, prefer to feel themselves to be the agent. Indeed, they will take a smaller payoff in order to have the feeling of being in control. Finally, Calvert et al. (2005) noted that, in a realistic computer game situation, young children will strive to gain control of the game, and that their engagement and attention are amplified when they do.

Most people are able to fairly accurately evaluate their own degree of control, although people diagnosed with schizophrenia and, to a lesser extent, those on the autism spectrum, resort to using only outcome monitoring and have difficulty using more diagnostic cues - like the directness of an effect - to make accurate judgments of agency (Metcalfe et al. 2014; Zalla et al. 2015). This inability to accurately assess their own agency can have profound consequences for many aspects of their lives. But some biases in the perception of agency, exhibited by other populations, can be beneficial. Older adults tend to feel that they are in control much of the time, even when, factually, they are not (Cosentino et al. 2011; Metcalfe et al. 2010). Taylor and Brown (1988) have argued that such illusions may have favorable outcomes for mental health, as well as for health-related behavior. Sustaining a self-concept of high agency, even if illusory, may foster perseverance in effective self-regulatory behavior and increase the odds of more favorable outcomes.

Judgments of agency influence and interact with the motivational and metacognitive components in the MAPS model. Agency as feeling can energize and motivate the desire to change. Lack of agency, or the feeling that one's efforts are ineffective, is related to depression, feelings of helplessness, and a lack of motivation - a potentially dire consequence for behavioral change. The feeling of agency is the opposite of feelings of helplessness or an inability to change our world and ourselves (Seligman and Maier 1974).

With regard to the antithesis of agency - helplessness - some research shows that passivity in the face of an aversive situation appears to be the default state, but that it can be overcome by learning that one can, in fact, control one's own outcomes (Maier and Seligman 2016). We can learn that we are agentic. Interestingly, these authors emphasize that therapeutic approaches that relate to future possible selves and are guided by metacognitive strategies are 
highly effective in overcoming feelings of helplessness (Maier and Seligman 2016). Taken together, these findings highlight the importance of the three components of the MAPS model working together to achieve outcomes, whether those outcomes are to do better in our coursework, to be physically fit, or to manage a mental health problem. Our perceptions of agency and our sense of control over future have cascading consequences for our future goals. It is important to note that goal pursuit can be an uncertain process, both internally and externally. It $t$ is also important to distinguish among the effects of certainty about goal achievement and the effects of certainty about the future. For example, whereas there are theories such as self-efficacy theory (Bandura and Adams 1977; Maddux 1995; Schunk and Pajares 2009), and expectancy value theories (Wigfield and Cambria 2010) that focus on the effects of certainty about one's ability to produce desired outcomes, there are also those theories that focus on the effects of lack of control over the future (Dequech 1999; Hermans and Dimaggio 2007). Agency provides both certainty and a sense of control to achieve future goals.

\section{Agency, metacognition, and learning}

Agency appears to have a strong impact on learning. But it also interacts with metacognition to influence behavior. For example, adult learners often have accurate metaknowledge of what needs to be studied. They will choose to study easy items when there is time pressure, but in the absence of time pressure they will choose to study more difficult items (Son and Metcalfe 2000). When people are asked to assess their ongoing learning, the judgments of learning that they make increase with study effort especially when effort is attributed to their own agency (Muenks et al. 2016). That is, if we attribute our increased effort to our own decisions, our judgments of learning are higher than when we attribute our effort to outside forces (Muenks et al. 2016). But a word of caution is in order. As noted in the section on metacognition, sometimes people have mistaken beliefs about the effectiveness of certain study strategies, a failure of metacognition. When that happens, correct metacognitive knowledge needs to be imparted to the individual in a manner that sustains rather than undermines their sense of agency. Furthermore, people often have implementation deficits (Metcalfe and Finn 2013; Metcalfe and Mischel 1999): they know what they need to do but they, nevertheless, fail to do it. They may also know what temptations they need to avoid but fail to avoid them. The metacognitive monitoring of outcomes, the attribution of those outcomes to the appropriate source, as well as the internal sense that derives from those attributions during goal pursuit that is, a calibrated belief in one's own agency — are all important in overcoming failures of willpower.

Although it is usually advantageous to be and to feel oneself to be agentic, there can be exceptions. An experiment by Taub et al. (2020) investigated the impact of agency on learning and memory in a game-based learning environment. This study is particularly instructive in illustrating not only advantages but also some potential disadvantages of highly agentic learning, pointing to the fact that agency is critical, but alone it is not enough to ensure good learning. Participants in Taub et al.'s (2020) experiment learned about infectious diseases by means of a learning environment called Crystal Island (an interactive digital environment). They studied in three ways: by listening to and studying comprehensive lectures and demonstrations of all information (no agency condition), by freely exploring all resources on three virtual islands (high agency condition), and by actively exploring the same three islands and all information, therein, but with constraints such as the requirement that all islands had to be 
visited and all resources therein had to be examined (which they called the low agency condition, but which we consider to be a 'guided' agency condition). As might be expected, participants in the no agency condition learned less, remembered less, were less engaged, and picked up less effective metacognitive strategies than did those in the agency conditions, even though they spent more time on task than did either agency group. Interestingly, though, the guided agency condition resulted in better learning than did the high agency condition. This occurred because people in the high agency condition often failed to use effective metacognitive strategies (including even such simple strategies as systematically and thoroughly studying all of the materials). Although agency appears to be central for learning and memory, in realistic learning situations the freedom to choose and control one's own learning needs to be constrained by well-thought-out metacognitive strategies or to be scaffolded by external guidance, in order to avoid distraction, mind-wandering, inattention, and other counterproductive pitfalls.

In summary, our feelings of agency influence our perception of ourselves and have consequences for our actions on several levels. First, agency occurs at the level of individual actions. We engage in actions which we believe can be effective. We avoid taking actions that we believe will have no impact. Second, agency operates at an intermediate level, that of knowing that the actions taken to get to the goal of learning are having an effect. As we dynamically monitor our actions, and we observe our world changing in the direction we favor as a result of those actions, we renew and strengthen our efforts in a positive feedback loop. Third, agency helps people feel that they are in control of their lives. For example, if a person feels as if their actions and behaviors affect the likelihood of getting to a particular goal - say, a grade on a test - then that person experiences an increased feeling of agency. Such a person sees, by looking at the consequences of his or her own intended actions, that he or she can not only change the grades but also change the self. Such an individual takes on what Dweck (2006) calls a 'growth mindset.' Agency, then, both independently and in conjunction with the other components of the MAPS model, is intrinsic to self-regulation and instrumental to goal striving and behavioral change.

\section{MAPS model of self-regulation}

Behavioral change in any domain requires self-regulation. The MAPS model of self-regulation (see Fig. 1) displays how the process of self-regulation is influenced by: 1) one's sense of self, and in particular, possible selves; 2) metacognitive knowledge and control that keep on track of, and provide feedback to maintain motivation over the long-term for goal achievement; and 3 ) the sense of agency, leading to motivated action, and that continually receives input from metacognitive monitoring of the effects of one's strategically guided actions, and at the same time feeds those attributions of one's effectiveness forward to one's self concept, to form a dynamic flow that guides goal-directed actions towards behavioral outcomes. Each of the components of the MAPS model have links both to one another and also to behavioral outcomes. Here we propose that the unique influences of possible selves, metacognition, and feelings of agency are enhanced when the interactive and synergistic effects are considered.

We propose that possible selves, will influence the metacognitive control strategies used to initiate and work toward behavior change. The ongoing metacognitive monitoring feeds back to maintain or modify possible selves, and concurrently supports or syphons off one's agency. 
When beliefs about agency change there is the potential to change metacognitive and control strategies, which may then affect possible selves. This dynamic and ongoing process represents self-regulation in real time.

We think this model is empirically testable. Though not the goal of this paper, the structure of the model lends itself to the development of specific hypotheses. Consider, for example, the relation of possible selves to the development of successful metacognitive control. An experiment could be designed in which we first assess people for their hoped-for and feared possible selves with respect to learning. A hoped-for possible self might be that with work, a student will become fluent in a new language, let us say, Igbo. A feared possible self might be that - even with a lot of work on learning the language, the student will never really master Igbo. Researchers can alert participants' attention to hoped-for possible selves or feared possible selves and then initiate an experiment in which a participant makes judgments of learning and has control over study strategies. If the model is correct, one would expect that the attention to one kind of possible self will affect judgments and directly affect the control strategies used. Additionally, a manipulation of degree of agency over study strategies could attenuate (positively or negatively) the impact of possible selves on judgments of learning. Model testing (e.g., mediation versus moderation) can be used to see how agency influences the connection between possible selves and metacognitive control influences (judgements of learning) in the study. Future research in our labs will investigate these matters.

Consider the first-semester college senior from the opening of this article. When she realizes that her goal of going on an internship is in jeopardy because of her poor academic performance, she is motivated to change her behavior. She sees a future self that she fears. In order to avoid failing her classes and losing the internship she uses her metacognitive knowledge to set up a daily schedule and more carefully monitor her assignments and to make sure she has completed her daily coursework and learned the material sufficiently that she will be prepared for the next assessments. She tests herself-a terrific metacognitive strategy to ensure learning. Each day she studies her readings until she is confident that she has mastered the content, then knowing that this feeling can be an illusion she tests herself again, and restudies the items she got wrong, using spaced practice (another terrific metacognitive strategy). Each night she checks off her accomplishments on her to-do list and charts her test progress - noting that it is getting better and better. This gives her a sense of agency and confidence that she has what it takes to pass her courses and be able to go on the internship. This sense feeds back into her self-concept as an effective person with a growth mindset and enhances her motivation to stay the course. This sense of herself as a resilient person buffers any setbacks she encounters, and she takes her mistakes and any unexpected outcomes as opportunities to learn more. She engages with her errors (another great metacognitive strategy). Ultimately, she improves her performance and earns the internship.

There are many contexts in addition to learning in which the independent and coactive roles of the components MAPS model can be applied to promote behavioral change. Elsewhere we have presented how the MAPS models applies to health (Frazier 2020). Each component is necessary, and they interact seamlessly to enhance self-regulation. We offer the MAPS model to demonstrate how goals embodied in possible selves, metacognitive knowledge and control strategies, and agency synergistically interact to influence people's motivation, action, selfperception, and performance, and ultimately lead to better outcomes. Although we have 
focused on learning outcomes, the MAPS model may be relevant behavioral change in other contexts such as health and work performance.

\section{Compliance with ethical standards}

Conflict of interest We have no known conflict of interest to disclose.

\section{References}

Allport, G. W. (1937). Personality: A psychological interpretation. New York: Holt \& Co..

Aloise-Young, P. A., Hennigan, K. M., \& Leong, C. W. (2001). Possible selves and negative health behaviors during early adolescence. The Journal of Early Adolescence, 21(2), 158-181. https://doi.org/10.1177/ 0272431601021002002.

Altintas, E., Karaca, Y., Moustafa, A., \& El Haj, M. (2020). Effect of best possible self intervention on situational motivation and commitment in academic context. Learning and Motivation, 69, 101599. https://doi.org/10. 1016/j.lmot.2019.101599.

Azevedo, R. (2015). Defining and measuring engagement and learning in science: Conceptual, theoretical, methodological, and analytical issues. Educational Psychologist, 50, 84-94. https://doi.org/10.1080/ 00461520.2015 .1004069 .

Bandura, A. (1989). Human agency in social cognitive theory. American Psychologist, 44(9), 1175-1184. https:// doi.org/10.1037/0003-066X.44.9.1175.

Bandura, A. (1999). Moral disengagement in the perpetration of inhumanities. Personality and Social Psychology Review, 3(3), 193-209. https://doi.org/10.1207/s15327957pspr0303_3.

Bandura, A. (2001). Social cognitive theory: An agentic perspective. Annual Review of Ppsychology, 52(1), 126. https://doi.org/10.1146/annurev.psych.52.1.1.

Bandura, A., \& Adams, N. E. (1977). Analysis of self-efficacy theory of behavioral change. Cognitive Therapy and Research, 1(4), 287-310. https://doi.org/10.1007/BF01663995.

Bertsch, S., Pesta, B. J., Wiscott, R., \& McDaniel, M. A. (2007). The generation effect: A meta-analytic review. Memory \& Cognition, 35(2), 201-210. https://doi.org/10.3758/BF03193441.

Bjork, R. A., Dunlosky, J., \& Kornell, N. (2013). Self-regulated learning: Beliefs, techniques, and illusions. Annual Review of Psychology, 64, 417-444. https://doi.org/10.1146/annurev-psych-113011-143823.

Boekaerts, M. (1996). Self-regulated learning at the junction of cognition and motivation. European Psychologist, 2, 100-112. https://doi.org/10.1027/1016-9040.1.2.100.

Brandtstädter, J. (1998). Action theory in developmental psychology. In R. M. Lerner (Ed.), Handbook of child psychology: Theoretical models of human development (5th ed., pp. 807-863). New York: Wiley.

Bucknoff, Z., \& Metcalfe, J. (2016). Feeling of agency predicts choice. International Meeting of the Psychonomic Society, Grenada, Spain.

Cadely, H. S. E., Pittman, J. F., Kerpelman, J. L., \& Adler-Baeder, F. (2011). The role of identity styles and academic possible selves on academic outcomes for high school students. Identity, 11(4), 267-288. https:// doi.org/10.1080/15283488.2011.613580.

Calvert, S. L., Strong, B. L., \& Gallagher, L. (2005). Control as an engagement feature for young children's attention to and learning of computer content. American Behavioral Scientist, 48(5), 578-589.

Carroll, P. J., Shepperd, J. A., \& Arkin, R. M. (2009). Downward self-revision: Erasing possible selves. Social Cognition, 27(4), 550-578. https://doi.org/10.1521/soco.2009.27.4.550.

Cleary, T. J., \& Sandars, J. (2011). Assessing self-regulatory processes during clinical skill performance: A pilot study. Medical Teacher, 33, e368-e374. https://doi.org/10.3109/0142159X.2011.577464.

Cleary, T. J., Callan, G. L., \& Zimmerman, B. J. (2012). Assessing self-regulation as a cyclical, context-specific phenomenon: Overview and analysis of SRL microanalytic protocols. Education Research International, 2012. https://doi.org/10.1155/2012/428639.

Cloutier, J., \& Macrae, C. N. (2008). The feeling of choosing: Self-involvement and the cognitive status of things past. Consciousness and Ccognition, 17(1), 125-135. https://doi.org/10.1016/j.concog.2007.05.010.

Cosentino, S., Metcalfe, J., Holmes, B., Steffener, J., \& Stern, Y. (2011). Finding the self in metacognitive evaluations: Metamemory and agency in nondemented elders. Neuropsychology, 25(5), 602-612. https:// doi.org/10.1037/a0023972.

de Place, A. L., \& Brunot, S. (2020). Motivational and behavioral impact of possible selves: When specificity matters. Imagination, Cognition and Personality, 39(4), 329-347. https://doi.org/10.1177/ 0276236619864275 . 
Dequech, D. (1999). Expectations and confidence under uncertainty. Journal of Post Keynesian Economics, 21(3), 415-430. https://doi.org/10.1080/01603477.1999.11490205.

DiBenedetto, M. K., \& Zimmerman, B. J. (2010). Differences in self-regulatory processes among students studying science: A microanalytic investigation. International Journal of Education and Psychological Assessment, 5, 2-24. https://doi.org/10.1080/00220973.2017.1409184.

Dietmeyer, D. L., Howsepian, B. A., \& Saenz, D. S. (2013). Possible selves and academic achievement. Children's Development Within Social Context: Volume I: Metatheory and Theory: volume Ii: Research and Methodology, 2, 181.

Dinsmore, D. L., Alexander, P. A., \& Loughlin, S. M. (2008). Focusing the conceptual lens on metacognition, self-regulation, and self-regulated learning. Educational Psychology Review, 20(4), 391-409. https://doi.org/ 10.1007/s10648-008-9083-6.

Dunlosky, J., \& Ariel, R. (2011). Self-regulated learning and the allocation of study time. Psychology of Learning and Motivation, 54, 103-140. https://doi.org/10.1016/B978-0-12-385527-5.00004-8.

Dunlosky, J., \& Tauber, S. K. (2014). Understanding people's metacognitive judgments: An isomechanism framework and its implications for applied and theoretical research. In T. Perfect \& D. S. Lindsay (Eds.), Handbook of applied memory (pp. 444-464). Thousand Oaks: Sage.

Dweck, C. S. (2006). Mindset: The new psychology of success. New York: Random House. https://doi.org/10. 4236/psych.2016.79125.

Dweck, C. S. (2018). Growth mindset interventions yield impressive results. The Conversation, 26.

Efklides, A. (2008). Metacognition: Defining its facets and levels of functioning in relation to self-and coregulation. European Psychologist, 13, 277-287. https://doi.org/10.1027/1016-9040.13.4.277.

Efklides, A. (2011). Interactions of metacognition with motivation and affect in self-regulated learning: The MASRL model. Educational Psychologist, 46(1), 6-25. https://doi.org/10.1080/00461520.2011.538645.

Efklides, A., \& Petkaki, C. (2005). Effects of mood on students' metacognitive experiences. Learning and Instruction, 15, 415-431. https://doi.org/10.1016/j.learninstruc.2005.07.010.

Efklides, A., \& Tsiora, A. (2002). Metacogntive experiences, self-concept, and self-regulation. Psychologia, 45, 222-236. https://doi.org/10.2117/psysoc.2002.222.

Efklides, A., Kourkoulou, A., Mitsiou, F., \& Ziliaskopoulou, D. (2006). Metacognitive knowledge of effort, personality factors, and mood state: Their relationships with effort-related metacognitive experiences. Metacognition and Learning, 1, 33-49. https://doi.org/10.1016/j.edurev.2005.11.001.

Efklides, A., Schwartz, B. L., \& Brown, V. (2018). Motivation and affect in self-regulated learning: Does metacognition play a role? In D. H. Schunk \& J. A. Greene (Eds.), Handbook of self-regulation of learning and performance (2nd ed., pp. 64-82). Abingdon: Routledge.

Erikson, M. G. (2007). The meaning of the future: Toward a more specific definition of possible selves. Review of General Psychology, 11(4), 348-358. https://doi.org/10.1037/1089-2680.11.4.348.

Erikson, M. G. (2019). Potentials and challenges when using possible selves in studies of student motivation. In H. Henderson, J. Stevenson, \& A. Bathmaker (Eds.), Possible selves and higher education: New interdisciplinary insights (pp. 13-26). Abingdon: Routledge.

Fisher, O., \& Oyserman, D. (2017). Assessing interpretations of experienced ease and difficulty as motivational constructs. Motivation Science, 3(2), 133-163. https://doi.org/10.1037/mot0000055.

Flavell, J. H. (1979). Metacognition and cognitive monitoring: A new area of cognitive-developmental inquiry. American Psychologist, 34(10), 906-911. https://doi.org/10.1037/0003-066X.34.10.906.

Frazier, L. D. (2020). Self-regulation in learning and life: The Health Psychology petri dish. Paper presented at the National Institute on the teaching of psychology. St. Pete Beach, FL.

Frazier, L. D., \& Hooker, K. (2006). Possible selves in adult development: Linking theory and research. In C. Dunkel \& J. Kerpelman (Eds.), Possible selves: Theory, research and applications (pp. 41-59). Hauppaug: Nova Publishers.

Frazier, L. D., Hooker, K., Johnson, P. M., \& Kaus, C. R. (2000). Continuity and change in possible selves in later life: A 5-year longitudinal study. Basic and Applied Social Psychology, 22(3), 237-243. https://doi.org/ 10.1207/S15324834BASP2203_10.

Freeman, S., Eddy, S. L., McDonough, M., Smith, M. K., Okoroafor, N., Jordt, H., \& Wenderoth, M. P. (2014). Active learning increases student performance in science, engineering, and mathematics. Proceedings of the National Academy of Sciences, 111(23), 8410-8415. https://doi.org/10.1073/pnas.1319030111.

Gollwitzer, P. M. (1999). Implementation intentions: Strong effects of simple plans. American Psychologist, 54(7), 493-503. https://doi.org/10.1037/0003-066X.54.7.493.

Gollwitzer, P. M., \& Sheeran, P. (2006). Implementation intentions and goal achievement: A meta-analysis of effects and processes. Advances in Experimental Social Psychology, 38, 69-119. https://doi.org/10.1016/ S0065-2601(06)38002-1.

Haase, C. M., Heckhausen, J., \& Wrosch, C. (2013). Developmental regulation across the life span: Toward a new synthesis. Developmental Psychology, 49(5), 964-972. https://doi.org/10.1037/a0029231. 
Hadwin, A., Järvelä, S., \& Miller, M. (2018). Self-regulation, co-regulation, and shared regulation in collaborative learning environments. In D. H. Schunk \& J. A. Greene (Eds.), Educational psychology handbook series. Handbook of self-regulation of learning and performance (pp. 83-106). Routledge/Taylor \& Francis Group: Abington.

Heckhausen, J., Wrosch, C., \& Schulz, R. (2019). Agency and motivation in adulthood and old age. Annual Review of Psychology, 70, 191-217. https://doi.org/10.1146/annurev-psych-010418-103043.

Hermans, H. J., \& Dimaggio, G. (2007). Self, identity, and globalization in times of uncertainty: A dialogical analysis. Review of General Psychology, 11(1), 31-61. https://doi.org/10.1037/1089-2680.11.1.31.

Hertzog, C. (2016). Aging and metacognitive control. In J. Dunlosky \& S. K. Tauber (Eds.), The Oxford handbook of metamemory (pp. 537-558). New York: Oxford University Press.

Higgins, E. T. (1987). Self-discrepancy: A theory relating self and affect. Psychological Review, 94(3), 319-340. https://doi.org/10.1037/0033-295X.94.3.319.

Higgins, E. T. (1989). Self-discrepancy theory: What patterns of self-beliefs cause people to suffer. Advances in Experimental Social Psychology, 22, 93-136. https://doi.org/10.1016/S0065-2601(08)60306-8.

Higgins, E. T. (1997). Beyond pleasure and pain. American Psychologist, 52, 1280-1300. https://doi.org/10. 1037/0003-066X.52.12.1280.

Higgins, E. T. (1998). Promotion and prevention: Regulatory focus as a motivational principle. Advances in Experimental Social Psychology, 30, 1-46. https://doi.org/10.1016/S0065-2601(08)60381-0.

Higgins, E. T. (2000). Making a good decision: Value from fit. American Psychologist, 55, 1217-1230. https:// doi.org/10.1037/0003-066X.55.11.1217.

Higgins, E. T., \& Cornwell, J. F. (2016). Securing foundations and advancing frontiers: Prevention and promotion effects on judgment and decision making. Organizational Behavior and Human Decision Processes, 136, 56-67. https://doi.org/10.1016/j.obhdp.2016.04.005.

Higgins, E. T., Roney, C. J., Crowe, E., \& Hymes, C. (1994). Ideal versus ought predilections for approach and avoidance distinct self-regulatory systems. Journal of Personality and Social Psychology, 66(2), 276-286. https://doi.org/10.1037//0022-3514.66.2.276.

Hooker, K. (1992). Possible selves and perceived health in older adults and college students. Journal of Gerontology, 47(2), P85-P95. https://doi.org/10.1093/geronj/47.2.P85.

Hooker, K. (1999). Possible selves in adulthood: Incorporating teleonomic relevance into studies of the self. In Social cognition and aging (pp. 97-122). New York: Academic Press.

Horowitz, E., Oyserman, D., Dehghani, M., \& Sorensen, N. (2020). Do you need a roadmaps or can someone give you directions: When school-focused possible identities change so do academic trajectories? Journal of Adolescence, 79, 26-38. https://doi.org/10.1016/j.adolescence.2019.12.013.

Kendi, I. X. (2019). How to be an antiracist. New York: Random House.

Kerpelman, J. L., \& Pittman, J. F. (2001). The instability of possible selves: Identity processes within late adolescents' close peer relationships. Journal of Adolescence, 24(4), 491-512. https://doi.org/10.1006/jado. 2001.0385.

King, L. A. (2002). Gain without pain? Expressive writing and self-regulation. In S. J. Lepore \& J. M. Smyth (Eds.), The writing cure: How expressive writing promotes health and emotional well-being (pp. 119-134). American Psychological Association. https://doi.org/10.1037/10451-006.

Kitsantas, A., \& Zimmerman, B. J. (2002). Comparing self-regulatory processes among novice, non-expert, and expert volleyball players: A microanalytic study. Journal of Applied Sports Psychology, 14, 91-105. https:// doi.org/10.1080/10413200252907761.

Knight, J. K., \& Wood, W. B. (2005). Teaching more by lecturing less. Cell Biology Education, 4(4), $298-310$. https://doi.org/10.1187/05-06-0082.

Knox, M. (2006). Gender and possible selves (pp. 61-77). In C. Dunkel \& J. Kerpelman (Eds.), Possible selves: Theory, research and applications. Hauppaug: Nova Publishers.

Ko, H. J., Mejía, S., \& Hooker, K. (2014). Social possible selves, self-regulation, and social goal progress in older adulthood. International Journal of Behavioral Development, 38(3), 219-227. https://doi.org/10.1093/ geront/gny159.

Koriat, A., Ma'ayan, H., \& Nussinson, R. (2006). The intricate relationships between monitoring and control in metacognition: Lessons for the cause-and-effect relation between subjective experience and behavior. Journal of Experimental Psychology: General, 135, 36-69. https://doi.org/10.1037/0096-3445.135.1.36.

Kornell, N., Hays, M. J., \& Bjork, R. A. (2009). Unsuccessful retrieval attempts enhance subsequent learning. Journal of Experimental Psychology: Learning, Memory, and Cognition, 35(4), 989. https://doi.org/10. $1037 / \mathrm{a} 0015729$.

Kortsch, G., Kurtines, W. M., \& Montgomery, M. J. (2008). A multistage longitudinal comparative (MLC) design stage II: Evaluation of the changing lives program (CLP): The possible selves questionnaireQualitative extensions (PSQ-QE). Journal of Adolescent Research, 23(3), 342-358. https://doi.org/10.1177/ 0743558408314382 . 
Kuhn, D. (2000). Metacognitive development. Current Directions in Psychological Science, 9, 178-181. https:// doi.org/10.1111/1467-8721.00088.

Lajoie, S. (2008). Metacognition, self-regulation, and self-regulated learning: A rose by any other name? Educational Psychology Review, 20, 469-475. https://doi.org/10.1007/s10648-008-9088-1.

Lee, S. J., \& Oyserman, D. (2009). Possible selves theory. In E. Anderman \& L. Anderman (Eds.), Psychology of classroom learning: An encyclopedia (pp. 695-698). Detroit: Macmillan.

Lee, J., Husman, J., Scott, K. A., \& Eggum-Wilkens, N. D. (2015). COMPUGIRLS: Stepping stone to future computer-based technology pathways. Journal of Educational Computing Research, 52(2), 199-223. https://doi.org/10.1177/0735633115571304.

Leondari, A., Syngollitou, E., \& Kiosseoglou, G. (1998). Academic achievement, motivation and future selves. Educational Studies, 24(2), 153-163. https://doi.org/10.1080/0305569980240202.

Leshikar, E. D., Dulas, M. R., \& Duarte, A. (2015). Self-referencing enhances recollection in both young and older adults. Aging, Neuropsychology, and Cognition, 22(4), 388-412. https://doi.org/10.1080/13825585. 2014.957150.

Maddux, J. E. (1995). Self-efficacy theory. In J. E. Maddux (Ed.), Self-efficacy, adaptation, and adjustment (pp. 3-33). Boston: Springer.

Maier, S. F., \& Seligman, M. E. P. (2016). Learned helplessness at fifty: Insights from neuroscience. Psychological Review., 123(4), 349-367. https://doi.org/10.1037/rev0000033.

Markus, H., \& Nurius, P. (1986). Possible selves. American Psychologist, 41(9), 954-969. https://doi.org/10. 1037/0003-066X.41.9.954.

Mason, L., Boldrin, A., \& Ariasi, N. (2010). Epistemic metacognition in context: Evaluating and learning online information. Metacognition Learning, 5, 67-90. https:/doi.org/10.1007/s11409-009-9048-2.

Metcalfe, J. (2013). "Knowing" that the self is the agent. In J. Metcalfe \& H. S. Terrace (Eds.), Agency and joint attention (pp. 238-255). London: Oxford University Press. https://doi.org/10.1093/acprof:oso/ 9780199988341.001 .0001$.

Metcalfe, J. (2017). Learning from errors. Annual Review of Psychology, 68, 465-489. https://doi.org/10.1146/ annurev-psych-010416-044022.

Metcalfe, J., \& Finn, B. (2013). Metacognition and control of study choice in children. Metacognition and Learning, 8, 19-46. https://doi.org/10.1007/s11409-013-9094-7.

Metcalfe, J., \& Greene, M. J. (2007). Metacognition of agency. Journal of Experimental Psychology: General, 136, 184-199. https://doi.org/10.1037/0096-3445.136.2.184.

Metcalfe, J., \& Mischel, W. (1999). A hot/cool system analysis of delay of gratification: Dynamics of willpower. Psychological Review, 106, 3-26. https://doi.org/10.1037/0033-295X.106.1.3.

Metcalfe, J., \& Schwartz, B. L. (2016). The ghost in the machine: Self-reflective consciousness and the neuroscience of metacognition. In J. Dunlosky \& S. K. Tauber (Eds.), Oxford library of psychology. The Oxford handbook of metamemory (pp. 407-424). Oxford: Oxford University press.

Metcalfe, J., \& Xu, J. (2017). Learning from one's own errors and those of others. Psychonomic Bulletin and Review, 25, 402-408. https://doi.org/10.3758/s13423-017-1287-7.

Metcalfe, J., Eich, T. S., \& Castel, A. D. (2010). Metacognition of agency across the lifespan. Cognition, 116(2), 267-282. https://doi.org/10.1016/j.cognition.2010.05.009.

Metcalfe, J., Van Snellenberg, J. X., DeRosse, P., Balsam, P., \& Malhotra, A. K. (2012). Judgements of agency in schizophrenia: an impairment in autonoetic metacognition. Philosophical Transactions of the Royal Society B, 376, 1391-1400.

Metcalfe, J., Van Snellenberg, J. X., DeRosse, P., Balsam, P., \& Malhotra, A. K. (2014). Judgments of agency in schizophrenia: An impairment in autonoetic metacognition. In The cognitive neuroscience of metacognition (pp. 367-387). Berlin: Springer.

Miele, D. B., Wager, T. D., Mitchell, J. P., \& Metcalfe, J. (2011). Dissociating neural correlates of action monitoring and metacognition of agency. Journal of Cognitive Neuroscience, 23(11), 3620-3636. https:// doi.org/10.1162/jocn_a_00052.

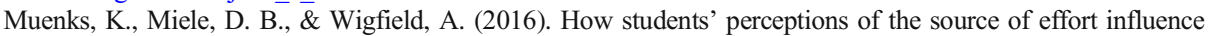 their ability evaluations of other students. Journal of Educational Psychology, 108(3), 438-454. https://oi. org/10.1037/edu0000068.

Muis, K. R., Pekrun, R., Azevedo, R., Sinatra, G. M., Trevors, G., Meier, E., \& Heddy, B. (2015). The curious case of climate change: Testing a theoretical model of epistemic beliefs, epistemic emotions, and complex learning. Learning and Instruction, 39, 168-183. https://doi.org/10.1016/j.learninstruc.2015.06.003.

Murty, V. P., DuBrow, S., \& Davachi, L. (2015). The simple act of choosing influences declarative memory. Journal of Neuroscience, 35(16), 6255-6264. https://doi.org/10.1523/JNEUROSCI.4181-14.2015.

Nelson, T. O., \& Narens, L. (1990). Metamemory: A theoretical framework and new findings. The Psychology of learning and motivation: Advances in research and theory, 26, 125-173. https://doi.org/10.1016/S00797421(08)60053-5. 
Nurius, P., Casey, E., Lindhorst, T., \& Macy, R. (2006). Identity health, stress, and support: Profiles of transition to motherhood among high risk adolescent girls. Possible selves: Theory, research and applications, 97121.

Oyserman, D. (2019). The essentialized self: Implications for motivation and self-regulation. Journal of Consumer Psychology, 29(2), 336-343. https://doi.org/10.1002/jcpy.1093.

Oyserman, D., \& Dawson, A. (2019). Identity-based motivation and the paradox of the future self: Getting going requires thinking about time (later) in time (now). Behavioral and Brain Sciences, 42. https://doi.org/10. 1017/S0140525X19000633.

Oyserman, D., \& Fryberg, S. (2006). The possible selves of diverse adolescents: Content and function across gender, race and national origin. In C. Dunkel \& J. Kerpelman (Eds.), Possible selves: Theory, research and applications (pp. 17-39). Hauppaug: Nova Publishers.

Oyserman, D., \& James, L. (2011). Possible identities. In S. J. Schwartz, K. Luyckx, \& V. L. Vignoles (Eds.), Handbook of identity theory and research (pp. 117-145). New York: Springer.

Oyserman, D., \& Lewis Jr., N. A. (2017). Seeing the destination AND the path: Using identity-based motivation to understand and reduce racial disparities in academic achievement. Social Issues and Policy Review, 11(1), 159-194. https://doi.org/10.1111/sipr.12030.

Oyserman, D., \& Markus, H. (1990). Possible selves in balance: Implications for delinquency. Journal of Social Issues, 46(2), 141-157. https://doi.org/10.1111/j.1540-4560.1990.tb01927.x.

Oyserman, D., \& James, L. (2008). Possible selves: From content to process. In K. Markman, W. M. P. Klein, \& J. A. Suhr (Eds.), The Handbook of Imagination and Mental Stimulation (pp. 373-394). New York, NY: Psychology Press.

Oyserman, D., Terry, K., \& Bybee, D. (2002). A possible selves intervention to enhance school involvement. Journal of Adolescence, 25(3), 313-326. https://doi.org/10.1006/jado.2002.0474.

Oyserman, D., Bybee, D., Terry, K., \& Hart-Johnson, T. (2004). Possible selves as roadmaps. Journal of Research in Personality, 38(2), 130-149. https://doi.org/10.1016/S0092-6566(03)00057-6.

Oyserman, D., Bybee, D., \& Terry, K. (2006). Possible selves and academic outcomes: How and when possible selves impel action. Journal of Personality and Social Psychology, 91(1), 188-204. https://doi.org/10.1037/ 0022-3514.91.1.188.

Oyserman, D., Destin, M., \& Novin, S. (2015). The context-sensitive future self: Possible selves motivate in context, not otherwise. Self and Identity, 14(2), 173-188. https://doi.org/10.1080/15298868.2014.965733.

Oyserman, D., Lewis Jr., N. A., Yan, V. X., Fisher, O., O'Donnell, S. C., \& Horowitz, E. (2017). An identitybased motivation framework for self-regulation. Psychological Inquiry, 28(2-3), 139-147. https://doi.org/ 10.1080/1047840X.2017.1337406.

Panadero, E. (2017). A review of self-regulated learning: Six models and four directions for research. Frontiers in Psychology, 8, 422. https://doi.org/10.3389/fpsyg.2017.00422.

Peters, M. L., Meevissen, Y. M., \& Hanssen, M. M. (2013). Specificity of the best possible self intervention for increasing optimism: Comparison with a gratitude intervention. Terapia Psicológica, 1(1), 93-100. https:// doi.org/10.4067/S0718-48082013000100009.

Pierce, C. (1970). Offensive mechanisms. In F. Barbour (Ed.), In the black seventies (pp. 265-282). Boston: Porter Sargent.

Pintrich, P. R. (2000). The role of goal orientation in self-regulated learning. In M. Boekaerts, P. R. Pintrich, \& M. Zeidner (Eds.), Handbook of self-regulation (pp. 452-502). San Diego: Academic Press.

Quinlan, S. L., Jaccard, J., \& Blanton, H. (2006). A decision theoretic and prototype conceptualization of possible selves: Implications for the prediction of risk behavior. Journal of Personality, 74(2), 599-630. https://doi.org/10.1111/j.1467-6494.2006.00386.x.

Rothbaum, F., Weisz, J. R., \& Snyder, S. S. (1982). Changing the world and changing the self: A two-process model of perceived control. Journal of Personality and Social Psychology, 42(1), 5-37. https://doi.org/10. 1037/0022-3514.42.1.5.

Ruvolo, A. P., \& Markus, H. R. (1992). Possible selves and performance: The power of self-relevant imagery. Social Cognition, 10(1), 95-124. https://doi.org/10.1521/soco.1992.10.1.95.

Ryff, C. D. (1991). Possible selves in adulthood and old age: A tale of shifting horizons. Psychology and Aging, 6(2), 286-295. https://doi.org/10.1037/0882-7974.6.2.286.

Sahakyan, L., Delaney, P. F., \& Kelley, C. M. (2004). Self-evaluation as a moderating factor of strategy change in directed forgetting benefits. Psychonomic Bulletin and Review, 11, 131-136. https://doi.org/10.3758/ BF03206472.

Scheier, M. F., Carver, C. S., Clark, M. \& Fiske, S. (2014). Cognition, affect, and self-regulation. Affect and cognition: 17th Annual Carnegie Mellon symposium on cognition.

Schunk, D. H. (2008). Metacognition, self-regulation, and self-regulated learning: Research recommendations. Educational Psychology Review, 20, 463-467. https://doi.org/10.1007/s10648-008-9086-3. 
Schunk, D. H., \& Greene, J. A. (2018). Handbook of self-regulation of learning and performance (2nd ed.). New York, Routledge. https://doi.org/10.4324/9781315697048.

Schunk, D. H., \& Pajares, F. (2009). Self-efficacy theory. In K. R. Wenzel \& A. Wigfield (Eds.), Educational psychology handbook series. Handbook of motivation at school (pp. 35-53). Oxfordshire: Routledge/Taylor Francis Group.

Seligman, M. (1991). EP (1975). Helplessness. On development, depression and death. New York: W. H. Freeman \& Co..

Seligman, M. E. P., \& Maier, S. F. (1974). Failure to escape traumatic shock. Journal of Experimental Psychology, 74, 1-9. https://doi.org/10.1037/h0024514.

Sinatra, G. M., \& Mason, L. (2013). Beyond knowledge: Learner characteristics influencing conceptual change. In S. Vosniadou (Ed.), International handbook of research on conceptual change (2nd ed., pp. 377-394). London: Springer.

Slamecka, N. J., \& Graf, P. (1978). The generation effect: Delineation of a phenomenon. Journal of Experimental Psychology: Human Learning and Memory, 4(6), 592-604. https://doi.org/10.1037/0278-7393.4.6.592.

Smith, J., \& Freund, A. M. (2002). The dynamics of possible selves in old age. The Journals of Gerontology Series B: Psychological Sciences and Social Sciences, 57(6), P492-P500. https://doi.org/10.1093/geronb/57. 6.P492.

Smith, G. C., \& Oyserman, D. (2015). Just not worth my time? Experienced difficulty and time investment. Social Cognition, 33(2), 85-103. https://doi.org/10.1521/soco.2015.33.2.1.

Smith, G. C., James, L. E., Varnum, M. E., \& Oyserman, D. (2014). Give up or get going? Productive uncertainty in uncertain times. Self \& Identity, 13(6), 681-700. https://doi.org/10.1080/15298868.2014. 919958.

Soderstrom, N. C., Clark, C. T., Halamish, V., \& Bjork, E. L. (2015). Judgments of learning as memory modifiers. Journal of Experimental Psychology: Learning, Memory, and Cognition, 41, 553-558. https:// doi.org/10.1037/a0038388.

Son, L. K., \& Metcalfe, J. (2000). Metacognitive and control strategies in study-time allocation. Journal of Experimental Psychology: Learning, Memory, and Cognition, 26(1), 204. https://doi.org/10.1037/02787393.26.1.204.

Son, L. K., \& Schwartz, B. L. (2002). The relation between metacognitive monitoring and control. In T. J. Perfect \& B. L. Schwartz (Eds.), Applied metacognition (pp. 15-38). Cambridge: Cambridge University Press. https://doi.org/10.1017/CBO9780511489976.003.

Stake, J. E., \& Nickens, S. D. (2005). Adolescent girls' and boys' science peer relationships and perceptions of the possible self as scientist. Sex Roles, 52(1-2), 1-11. https://doi.org/10.1007/s11199-005-1189-4.

Steiner, M., van Loon, M. H., \& Bayard, N. S. (2020). Development of children's monitoring and control when learning from texts: Effects of age and test format. Metacognition Learning, 15, 3-27. https://doi.org/10. 1007/s11409-019-09208-5.

Stokes, V. (2019). Self-efficacy and the future selves construct: Strategies in support of adult learners' academic performance. In G. I. Strohschen \& K. Lewis (Eds.), Competency-based and social-situational approaches for facilitating learning in higher education (pp. 136-163). Philadelphia: IGI Global.

Sue, D. W., Capodilupo, C. M., Torino, G. C., Bucceri, J. M., Holder, A., Nadal, K. L., \& Esquilin, M. (2007). Racial microaggressions in everyday life: Implications for clinical practice. American Psychologist, 62(4), 271-286. https://doi.org/10.1037/0003-066X.62.4.271.

Sui, J., \& Humphreys, G. W. (2015). The integrative self: How self-reference integrates perception and memory. Trends in Cognitive Sciences, 19(12), 719-728. https://doi.org/10.1016/j.tics.2015.08.015.

Taub, M., Sawyer, R., Smith, A., Rowe, J., Azevedo, R., \& Lester, J. (2020). The agency effect: The impact of student agency on learning, emotions, and problem-solving behaviors in a game-based learning environment. Computers \& Education, 147, 103781. https://oi.org/10.1016/j.compedu.2019.103781.

Taylor, S. E., \& Brown, J. D. (1988). Illusion and well-being: A social psychological perspective on mental health. Psychological Bulletin, 103(2), 193. https://doi.org/10.2307/3033698.

Toppino, T. C., Lavan, M. H., \& Iaconelli, R. T. (2018). Metacognitive control in self-regulated learning: Conditions affecting the choice of restudying versus retrieval practice. Memory \& Cognition, 46, 1164 1177. https://doi.org/10.3758/s13421-018-0828-2.

vanDellen, M. R., \& Hoyle, R. H. (2008). Possible selves as behavioral standards in self-regulation. Self and Identity, 7(3), 295-304. https://doi.org/10.1080/15298860701641108.

Vignoles, V. L., Manzi, C., Regalia, C., Jemmolo, S., \& Scabini, E. (2008). Identity motives underlying desired and feared possible future selves. Journal of Personality, 76(5), 1165-1200. https://doi.org/10.1111/j.14676494.2008.00518.x.

Vohs, K. D., \& Baumeister, R. F. (Eds.). (2016). Handbook of self-regulation: Research, theory, and applications. New York: Guilford Publications.

Wells, A. (2008). Metacognitive therapy for anxiety and depression. Guilford Press. 
Wigfield, A., \& Cambria, J. (2010). Expectancy-value theory: Retrospective and prospective. Advances in Motivation and Achievement, 16 (part a), 35-70. https://doi.org/10.1108/S0749-7423(2010)000016A005.

Winne, P. H. (2014). Issues in researching self-regulated learning as patterns of events. Metacognition and Learning, 9, 229-237. https://doi.org/10.1007/s11409-014-9113-3.

Winne, P. H. (2018). Theorizing and researching levels of processing in self-regulated learning. British Journal of Educational Psychology, 88, 9-20. https://doi.org/10.1111/bjep.12173.

Wrosch, C. (2011). Self-regulation of unattainable goals and pathways to quality of life. In S. Folkman (Ed.), The Oxford handbook of stress, health, and coping (pp. 319-333). Oxford: Oxford University Press.

Wrosch, C., Scheier, M. F., Carver, C. S., \& Schulz, R. (2003). The importance of goal disengagement in adaptive self-regulation: When giving up is beneficial. Self and Identity, 2(1), 1-20. https://doi.org/10.1080/ 15298860309021.

Zalla, T., Miele, D., Leboyer, M., \& Metcalfe, J. (2015). Metacognition of agency and theory of mind in adults with high functioning autism. Consciousness and Cognition, 31, 126-138. https://doi.org/10.1016/j.concog. 2014.11.001.

Zimmerman, B. J. (1986). Becoming a self-regulated learner: Which are the key subprocesses? Contemporary Educational Psychology, 11(4), 307-313. https://doi.org/10.1016/0361-476X(86)90027-5.

Zimmerman, B. J. (2000). Attaining self-regulation: A social cognitive perspective. In M. Boekaerts, P. R. Pintrich, \& M. Zeidner (Eds.), Handbook of self-regulation (pp. 13-39). Cambridge: Academic Press. https://doi.org/10.1016/B978-012109890-2/50031-7.

Zimmerman, B. J. (2013). From cognitive modeling to self-regulation: A social cognitive career path. Educational Psychologist, 48(3), 135-147. https://doi.org/10.1080/00461520.2013.794676.

Zimmerman, B. J., \& Bandura, A. (1994). Impact of self-regulatory influences on writing course attainment. American Educational Research Journal, 31, 845-862. https://doi.org/10.3102/00028312031004845.

Publisher's note Springer Nature remains neutral with regard to jurisdictional claims in published maps and institutional affiliations. 